\title{
Experimental Study on the Seismic Performance of a Partition Damped Wall-Filled Frame Structure
}

\author{
Shuainan Zhai $\mathbb{D}^{1,2}$ Zuyin Zou, ${ }^{1,2}$ Zhanyuan Zhu $\mathbb{D}^{1,2}$ Zixing Zhang, ${ }^{1,2}$ Wei Liang ${ }^{10},{ }^{1,2}$ \\ Xuanhao Cheng, ${ }^{1,2}$ and Shuzhen Chang ${ }^{1,2}$ \\ ${ }^{1}$ College of Civil Engineering, Sichuan Agricultural University, Dujiangyan, Sichuan 611830, China \\ ${ }^{2}$ Sichuan Higher Education Engineering Research Center for Disaster Prevention and Mitigation of Village Construction, \\ Sichuan Agricultural University, Dujiangyan, Sichuan 611830, China
}

Correspondence should be addressed to Zhanyuan Zhu; zhuzyuan910@163.com

Received 25 August 2019; Revised 6 October 2019; Accepted 4 November 2019; Published 23 November 2019

Academic Editor: Chao Tao

Copyright (C) 2019 Shuainan Zhai et al. This is an open access article distributed under the Creative Commons Attribution License, which permits unrestricted use, distribution, and reproduction in any medium, provided the original work is properly cited.

\begin{abstract}
In the past, earthquakes have caused significant damage to traditional masonry filler wall frame structures. To solve this problem, a new design scheme, the partition damping filler wall, is proposed in this paper to reduce the interaction between the filler wall and the frame structure. Low cyclic loading tests are carried out on the traditional and the new masonry filler wall frames. Besides, one full-scale-angled span layer frame without a filler wall is produced for comparison analysis. The mechanical performances of the different frames are studied, including the characteristics of the deformation failure modes, hysteretic curves, skeleton curves, rigidity degeneration, energy dissipation capacity, and the lateral displacement of the frame columns. The research results show that the partition damping filler wall can significantly decrease the diagonal bracing effect of the filler wall on the steel frame. Meanwhile, the setting of the low-strength mortar between the filler wall and steel frame and the arrangement of the damping layer can improve the stress distribution and delay the crack development of the wall. Furthermore, the stiffness degradation rate of the partition damping filler wall is obviously slower than that of the traditional masonry filler wall frame structure. In this paper, the partition damped wall-filled frame structure shows outstanding ductility and deformation capacity.
\end{abstract}

\section{Introduction}

The frame structure is a typical architectural structure. It is widely used, because it is easy to build, have a good insulation of temperature preservation, and low cost of a project. In the standard of many countries, masonry filler wall structures are often considered as nonstructural components, so they are ignored in the calculation [1-6]. In various kinds of seismic investigation, it is found that these nonstructural components have been seriously damaged under the action of the earthquake, which will also cause the damage of structural components, thus leading to the whole structure failure [7-10]. In the past decades, many scholars have studied on the seismic vulnerability of masonry filler wall frame structure, aiming to analyze the interaction between the traditional masonry filler wall and the frame structure and reduce the damage of frame and masonry filler wall under the action of the earthquake [11-15].

The filler materials of the traditional masonry filler walls are completely in contact with the surrounding frame structure, and there is no gap with the frame. The masonry filler walls are supported within the frame, increasing the overall stiffness of the structure [16]. At this point, the structural system is equivalent to the box structure supporting the frame structure, and its deformation is controlled by the shear behavior of the filler wall, rather than the typical bending plastic hinge of the empty frame [17]. In the design process, the interaction between the masonry filler and the frame is usually estimated by the simplified model of diagonal equivalent diagonal bracing without too much analysis [18-20]. In recent years, researchers have innovatively proposed different masonry filler schemes for the 
damage of frame filler walls in earthquakes. These solutions include the partitioning of the filler wall [17, 21-29], the use of replacement joints to replace mortar (dry or plastic joints) [30-35], and the construction of the filler with deformable materials $[36,37]$. The purpose of all these is to reduce frame failure by reducing the interaction between the filler wall and the frame, thereby reducing the contact force between the frame and the filler. In the research on the partition technology of the filler wall, Zhou et al. [23-25] divided the filler wall into several masonry units by setting the damping layer horizontally in the filler wall (SBS-modified asphalt coil) and formed the structure scheme of the damping filler wall unit arranged alternately by the masonry unit and damping layer, which improved the seismic performance of the frame filler wall. Preti et al. $[17,22]$ and Preti and Bolis [29] proposed a variable filler type with a horizontal sliding joint, thereby reducing the interaction between the filler wall and the frame and limiting the damage to the masonry. At the same time, an analytical formula based on geometric and mechanical properties is proposed to describe the inplane response of the filler material and its interaction with the boundary frame [38]. Morandi et al. [28] referred the works of Mohammadi et al. [39] and Preti et al. [17, 22], conceived a new earthquake-resistant clay masonry filler system, applied different innovative materials to implement flexible and sliding joints, and conducted experimental research. Bolis et al. [40, 41] used numerical analysis to investigate the role of openings in the inplane response of filled reinforced concrete frames when masonry filling with sliding subpanels. The test was conducted to test the effect of the full-height opening on the inplane performance under the lateral load of the masonry infill wall separated by the horizontal sliding joint. Graziotti et al. [42, 43] conducted out-of-plane studies of frame structures filled with different masonry structures under earthquake action, and the results showed that the frame structures filled with different masonry structures had different failure mechanisms. Ozturkoglu et al. [44] analyzed the possible effects of the infill wall openings on the seismic performance of reinforced concrete frames through pushover analysis of bare, partially filled, and fully filled frames with different spacings and layers.

Based on the relevant scholars on the research of the filler wall partition technology foundations, this paper proposes a new type of filler wall design. This scheme improves the stiffness of the structure and the energy dissipation capacity, reduces the earthquake under the action of the structure of the lateral and plane in the interaction of filler wall and frame, avoids stiffness mutation caused by the "thin-layer," "strong-beam weak-column," and "short-column destruction-associated failure damage," and implementing "beneficial effects on the stiffness effect of small earthquake" and "an adverse influence on decreasing stiffness" expectations of a mechanism. In addition, low cyclic load tests are carried out on the traditional masonry filler wall frame structure and the new partition-type damping filler wall frame structure and analyzed the different seismic performances of them.

\section{Experiment}

2.1. Sample Design and Manufacture. Based on the height and column grid of a common residential building span and the size of the column sections and beam sections, the design of a full-scale model was developed for three common modes. One frame used was the traditional masonry filler wall steel frame (TMWF). Another frame used was a partition damping filler wall steel frame (PDWF). The trusses were an unfilled wall steel frame (UWF) with welded steel beams and columns, using steel Q345 and type E50 welding rods. The columns are $\mathrm{H} 300 \times 300 \times 10 \times 16$, the beams are $\mathrm{H} 400 \times 300 \times 10 \times 16$, the floor height is $3000 \mathrm{~mm}$, and the span is $5400 \mathrm{~mm}$. Beam and column joints are bolted together with cantilever beam ends [45]. The elevation diagram of the frame geometry size and the joint details of beams and columns are shown in Figures 1 and 2 .

The wall's filling material is an MU3.5-sintered hollow brick and M5 mortar with a thickness of $200 \mathrm{~mm}$. When the length of the wall exceeds $5 \mathrm{~m}$, according to the Code for Design of Masonry Structures (GB 50003-2011) [46], a constructional column is added in the middle of the wall with a concrete strength grade of C20 and a section size of $240 \mathrm{~mm} \times 200 \mathrm{~mm}$. As shown in Figures 3(b) and 3(c), a tensile steel bar is set up every $400 \mathrm{~mm}$ along the wall height; the length extending into the wall is $700 \mathrm{~mm}$, and the diameter is $6 \mathrm{~mm}$. The tensile steel bar cannot slide relative to the frame column.

In the test of the traditional masonry filler wall frame structure, the filler wall is in close contact with the frame column. The solid-sintered brick is placed on top of the frame beam at a slanting angle and filled with mortar; horizontal tensile bars are extended into the column and wall. In the structure of the partition damping filler wall, the joints between the filler wall and the frame column are filled with low-strength mortar at a thickness of $20 \mathrm{~mm}$. SBSmodified asphalt coils are laid at the connection between the filler wall and the top and bottom beams of the frame. A damping layer is used to separate the wall. In the damping layer, the rigid layer is a steel plate (number: Q235) with a thickness of $4 \mathrm{~mm}$, a width of $180 \mathrm{~mm}$, and a length of $2270 \mathrm{~mm}$; the viscoelastic material layer is $3 \mathrm{~mm}$ thick SBSmodified asphalt rolling material. Schematic diagrams of the damping layer structure and the schematic diagram of each mode structure scheme are shown in Figures 3 and 4.

2.2. Material Properties. According to the relevant provisions of Test Methods for Brick Wall Bricks (GB/T25422012) [47] and Standards for Testing Basic Performance of Building Mortars (JGJ/T 70-2009) [48], the sintered hollow bricks, masonry mortar, and low-strength mortar used in the test are measured. The test chart is shown in Figure 5. The measured compressive strength is shown in Table 1.

2.3. Loading Plan. The experiment was carried out in the Engineering Structure and Mechanics Experiment Center of Sichuan Agricultural University. The experimental system of 


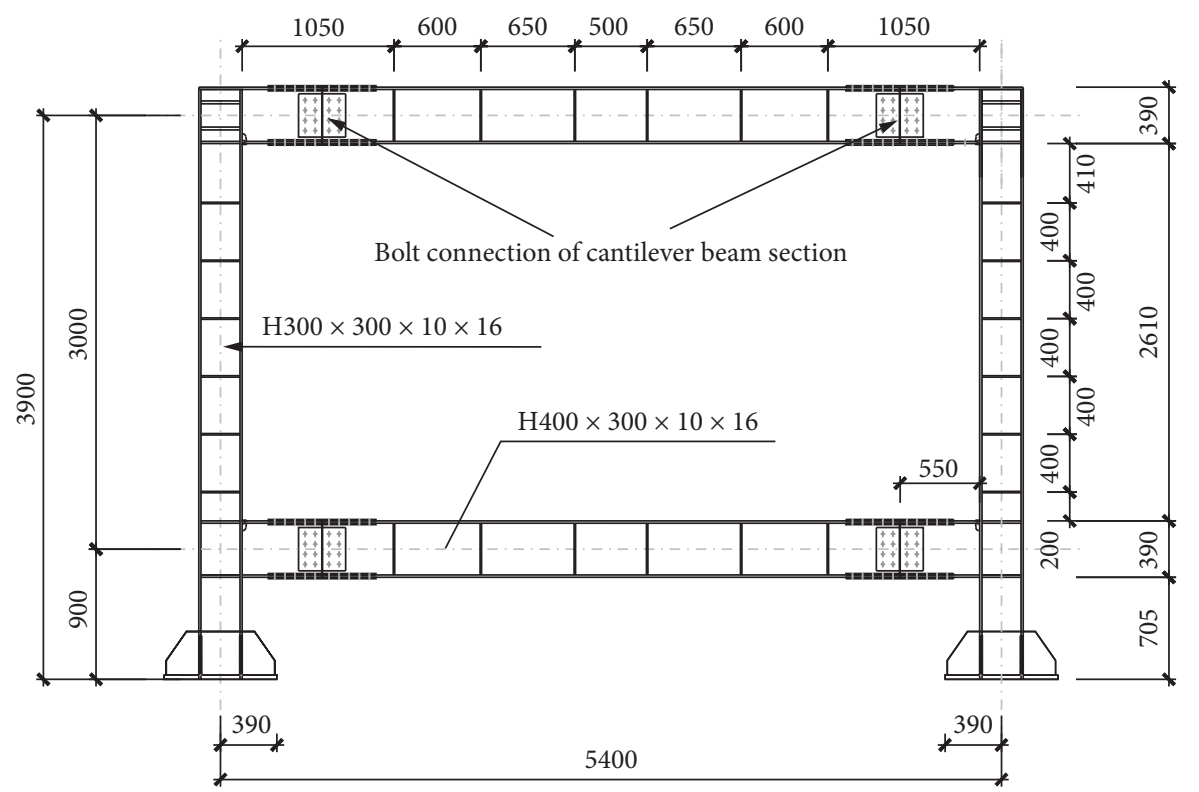

Figure 1: Geometric dimension elevation of the frame.
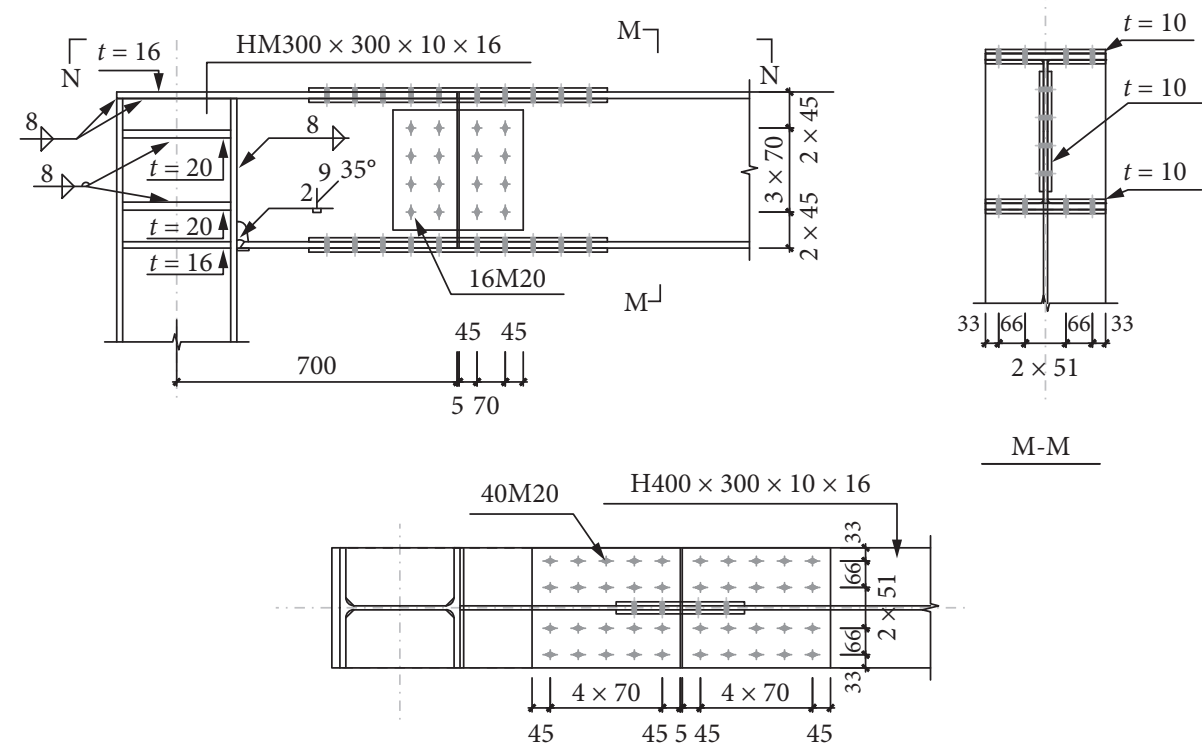

$\mathrm{M}-\mathrm{M}$

$$
\mathrm{N}-\mathrm{N}
$$

FIgUre 2: Details of a beam-column joint.

an electrohydraulic servo loading structure (R-9200ND) was used in the test. A horizontal low-cycle repeated load was applied to the frame by the electrohydraulic servo actuator with a push and pull force of $800 \mathrm{kN}$. One end of the horizontal actuator was connected to the end of the frame beam by bolts, and the other end was fixed on the reaction wall by the steel cushion beam. The test load and constraint devices are shown in Figure 6. Considering that the main purpose of the test is to analyze the horizontal hysteretic energy dissipation characteristics of the mode, the bolts used to fix the steel frame in the test are sufficient to avoid overturning the frame during the test. Therefore, no vertical load was applied during the test.

This test designs the loading scheme in accordance with relevant requirements of the Specification for Seismic Test of Buildings (JGJ/T 101-2015) [49] and adopts the force-displacement mixed loading system for loading. The test loading system is shown in Figure 7. The specifications of the loading system are as follows. Before the wall cracks, the load control and hierarchical load are measured. Once cracking begins, the force-control is stopped and unloaded to $0 \mathrm{kN}$, and then the displacement-control loading is started. In the 


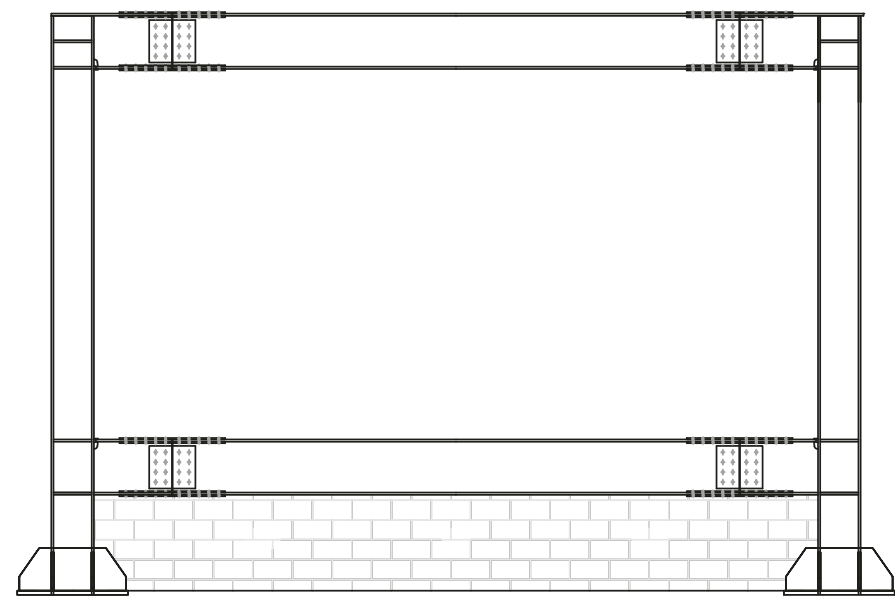

(a)

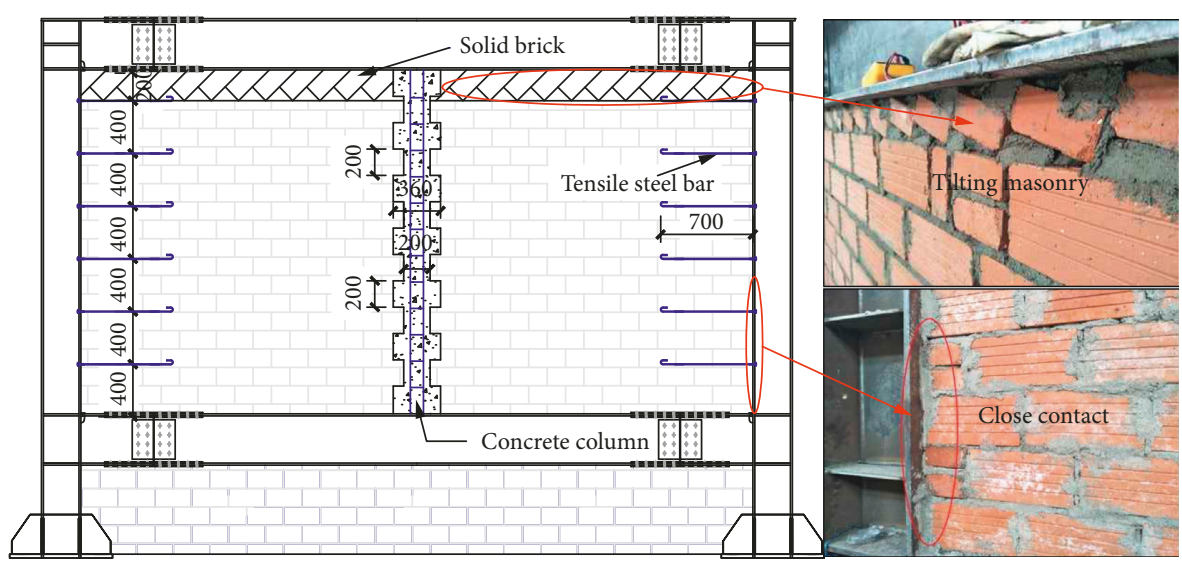

(b)

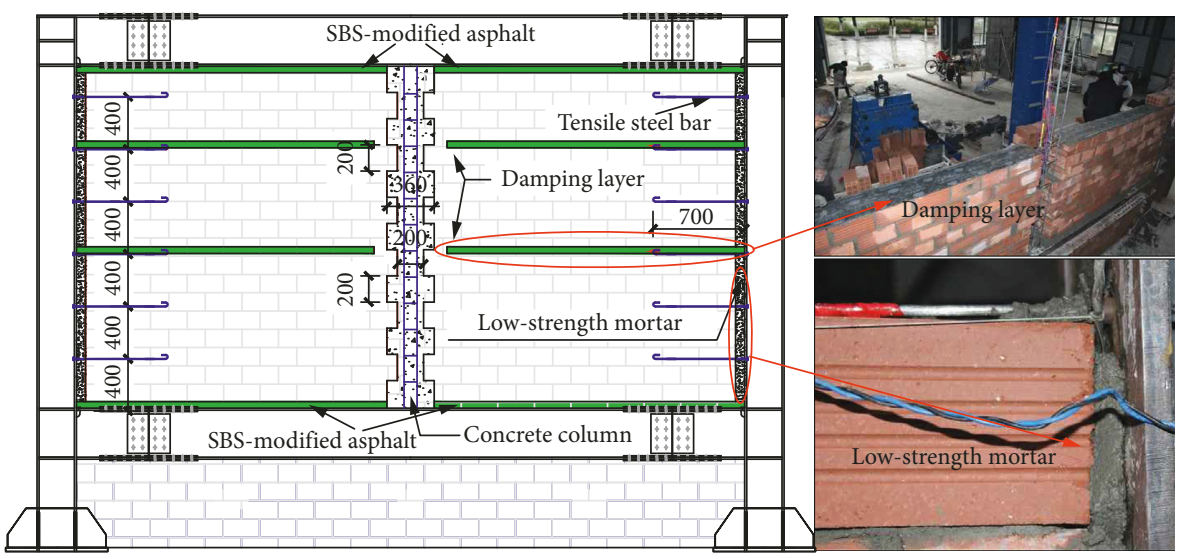

(c)

FIGURE 3: Schematic diagrams of damping layer structure and each mode structure. (a) UWF construction scheme. (b) Sample TMWF construction scheme. (c) PDWF construction scheme.

first loading cycle, the maximum displacement $\delta$ is controlled and consisted with the cracking displacement recorded in the force-control part, and in the subsequent displacement loading cycles, the maximum loading displacement increases by $0.5 \delta$ each cycle. When the wall is destroyed (severe cracks in masonry filler wall) or a serious tilt occurs, the modes stop loading.
2.4. Measuring Content and Point Arrangement. To achieve the purpose of the test, the main content of the measurements is required; this includes the load borne by the mode, the strain of the frame beams and columns, the horizontal displacement, wall cracks, and etc. The main content of the measurements and the selection of instruments are shown in Table 2, and the layout of each measuring point is shown in Figure 8. 


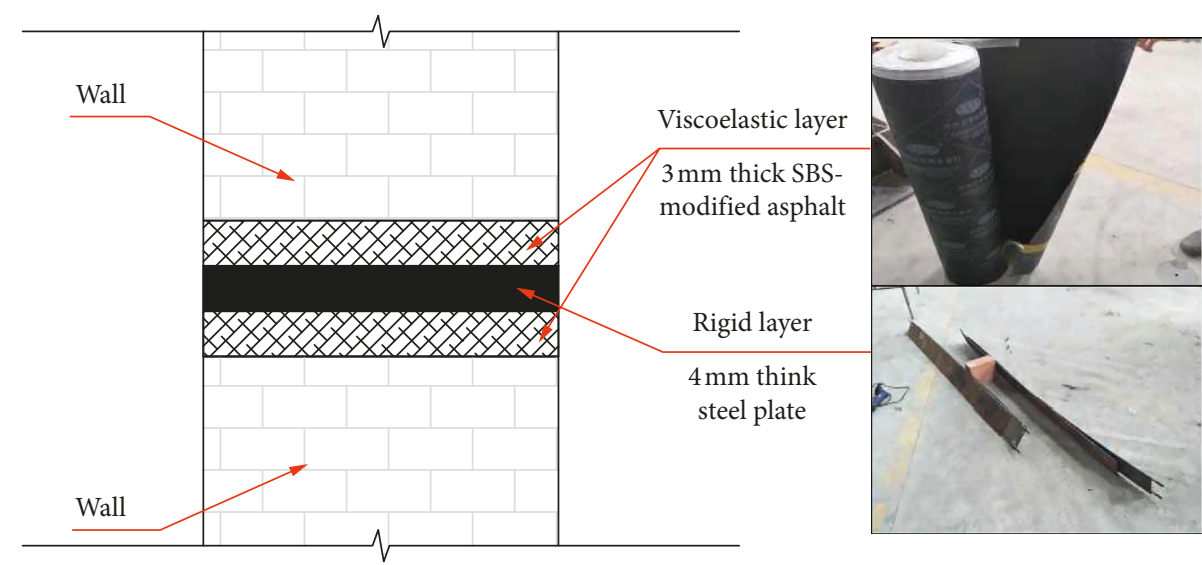

FIGURE 4: Schematic diagram of damping layer construction.

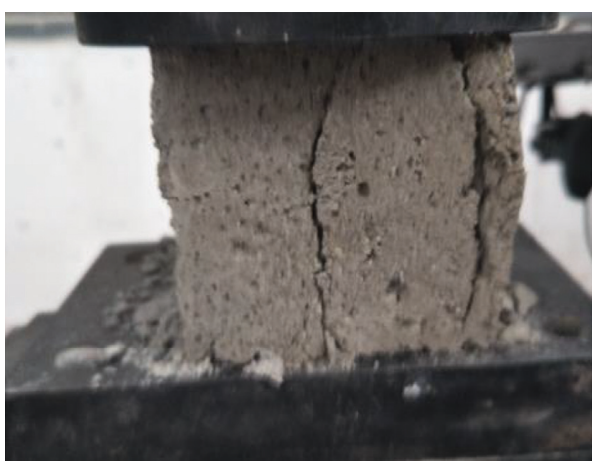

(a)

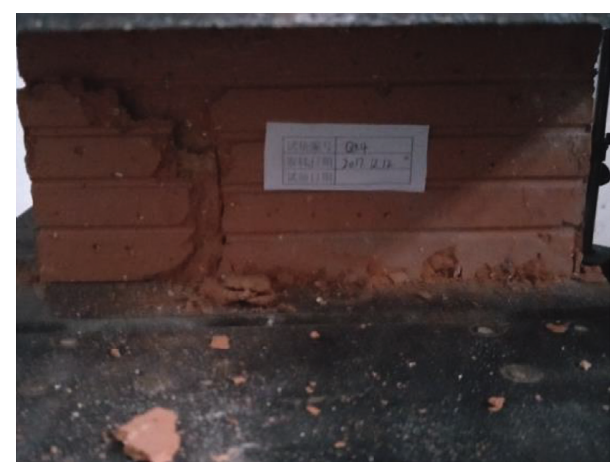

(b)

FIGURE 5: Material mechanical properties test. (a) Mortar mechanics test. (b) Mechanical properties test of sintered hollow brick.

TABLE 1: Test material measured compressive strength.

\begin{tabular}{lcc}
\hline Test material & Size $(\mathrm{mm}) / \mathrm{mix}$ ratio & Average compressive strength $(\mathrm{MPa})$ \\
\hline Sintered hollow brick & $240 * 180 * 90$ & 3.8 \\
Masonry mortar & (length $*$ width $*$ height) & 2.2 \\
Low-strength mortar & $1.23: 1: 6.02$ & 5.3 \\
\hline
\end{tabular}

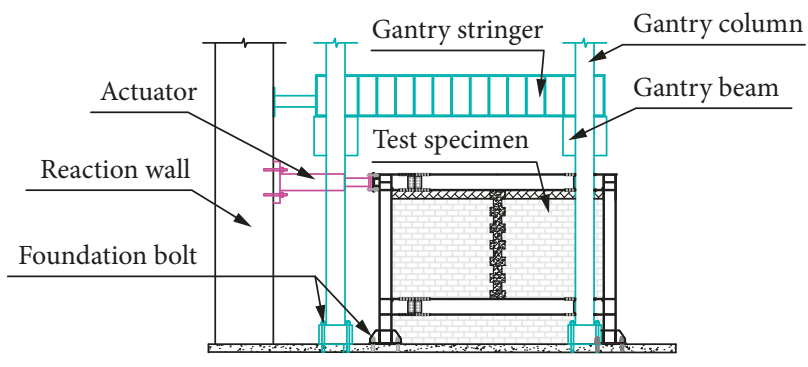

(a)

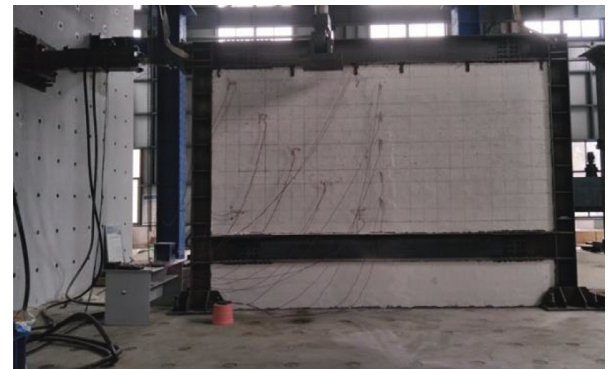

(b)

Figure 6: Test load and restraint device. (a) Schematic diagram of the test loading system. (b) Loading field drawing. 


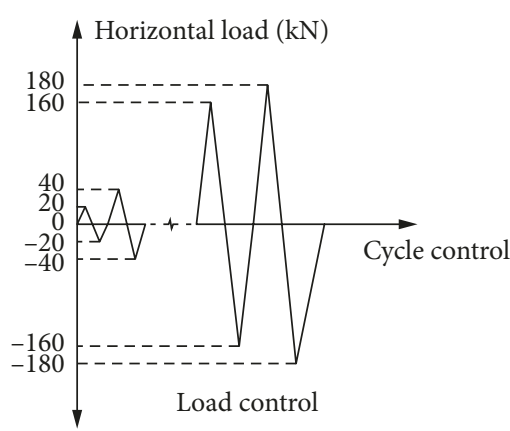

(a)

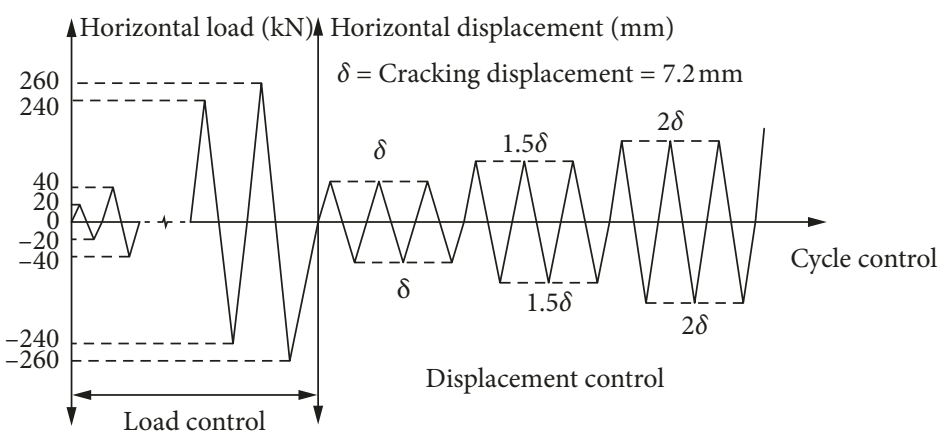

(b)

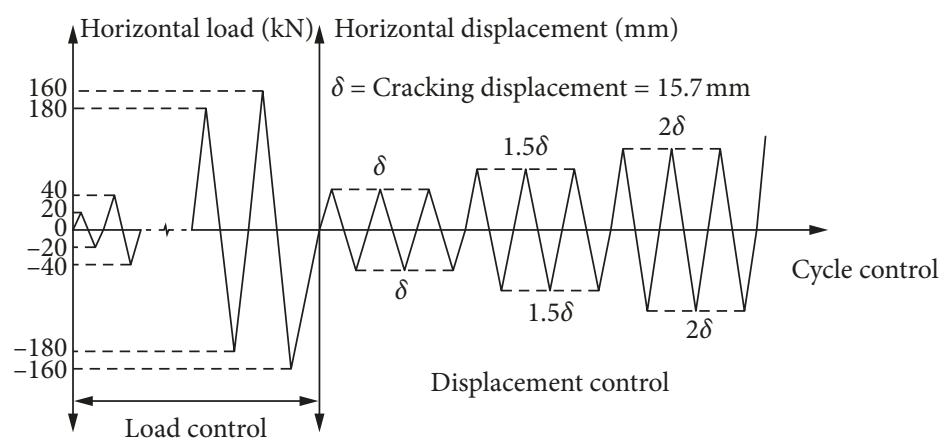

(c)

Figure 7: Test loading system: (a) UWF, (b) TMWF, and (c) PDWF.

TABLE 2: Main content of the measurements and the selection of instruments.

Test content

Hysteresis curve

Frame beam-column strain

Frame beam-column displacement
Instrument

Electrohydraulic servo system, displacement meter Electrical resistance strain gauge, strain rosette Displacement meter

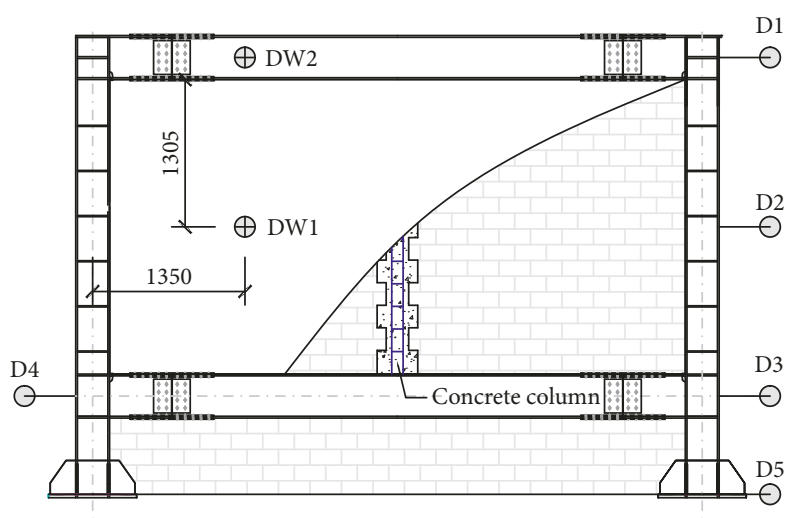

(a)

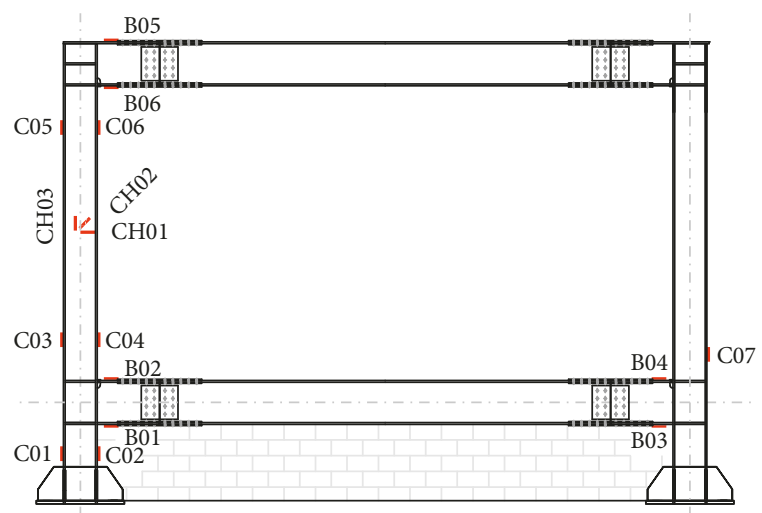

- Electrical resistance strain gage

I Strain rosette

(b)

FIGURE 8: Layout of measuring points: (a) lateral displacement survey layout of steel frame and (b) steel frame strain measurement layout. 


\section{Test Results and Analysis}

\subsection{Comparative Analysis of Failure Process}

(1) The failure phenomena of the TMWF and PDWF modes with the same lateral movement were compared and analyzed. During a loading cycle of $21.9 \mathrm{~mm}$ displacement, more stepped cracks and horizontal cracks had formed in the TMWF wall. In particular, there was a certain penetration trend of stepped cracks in the left wall, while no obvious cracks were observed in the PDWF wall. During the loading cycle of $29.1 \mathrm{~mm}$ displacement, cracks appeared in the PDWF wall, but the development of the PDWF wall was slow. The original cracks did not continue to expand, and the development trend of cracks was not obvious. However, the cracks of the TMWF wall connected with each other to form obvious ladder cracks. When the displacement load reached $32.1 \mathrm{~mm}$, the TMWF wall showed obvious shaking, blocks were damaged and fell off, and the wall was seriously damaged. However, the PDWF wall only partially showed step-type cracks and horizontal cracks, but no penetrating cracks were formed. In the case of ultimate failure, the wall cracks of the TMWF were mainly $x$-shaped cross oblique cracks with a small number of horizontal cracks, while the PDWF showed mainly horizontal cracks with only a small number of local oblique cracks. The final failure diagram of the two modes is shown in Figure 9.

(2) By contrasting the mode cracking degree, it can be found that under the condition of the same lateral movement, the partition damping filler wall damage was always lighter than the traditional masonry filler wall. The construction measures and the setting of middle-strength and lower-strength mortar have a direct relationship for damping filler wall partition types. When load displacement reaches a certain value, low-strength mortar is undermined, and the force effect wanes. With late loading, the lowstrength mortar is destroyed, although its failure can be used to isolate the destruction of the interaction of the filling wall and the frame. When the main frame with a filler wall is released and no longer subject to force, the filler wall diagonal brace effect is obviously weakened; this ensures that the framework is free of deformation. The ductility of the structure is improved, and the filler wall is effectively protected.

(3) Comparing the TMWF and PDWF modes, the damage in each example and their eventual destruction was evident. For the TMWF wall, there were mainly $x$-shaped cross cracks; however, the PDWF wall showed mainly horizontal cracks. This is because the rigid layer damping layer of the PDWF blocked the path of the filler wall-inclined cracks and changed the internal force distribution and the filler wall crack propagation direction. At the same time, the filler wall destruction was mainly shear failure.
3.2. Comparative Analysis of Hysteresis Curves. Figure 10 shows the load-displacement hysteretic loop curve of each mode. It can be found from the figure, due to the influence of the filler wall on the frame structure, that the shapes of the hysteretic loop curves of TMWF and PDWF are significantly different from that of UWF at the early loading stage. With the increase of the loading displacement, the hysteretic shapes of TMWF and PDWF were significantly different in the late loading stage. The phenomenon of "pinching" of the TMWF mode was obvious, while the "pinching" in the PDWF mode was basically absent. The curved shape was fusiform, which was fuller than that of the TMWF. This shows the different energy dissipation mechanisms of the two modes. The TMWF wall mainly relies on the wall stress to produce cracking failure and coulomb friction energy dissipation between cracks, while the PDWF wall consumes energy through the failure of low-strength mortar between the wall frame and the reciprocating shear viscoelastic material layer of the rigid layer and masonry. By comparing the hysteretic ring shape and area of the PDWF and TMWF walls under loading cycles at all levels, it was found that the hysteretic ring shape and area of PDWF under loading cycles at all levels were more uniform, and the hysteretic energy dissipation performance was more stable.

3.3. Comparative Analysis of Skeleton Curves. The skeleton curves of each mode were drawn, as shown in Figure 11. Through comparative analysis of the skeleton curves of the three modes, it was found that the initial stiffness of TMWF $(53.7 \mathrm{KN} / \mathrm{mm})$ and PDWF $(24.7 \mathrm{KN} / \mathrm{mm})$ was 6.16 times and 2.29 times higher than that of UWF $(7.5 \mathrm{KN} / \mathrm{mm})$, respectively; this was due to the influence of the filling wall on the frame structure, and the initial stiffness of PDWF was $46 \%$ of that of TMWF. It is shown that the filler walls of the two construction methods can provide a certain lateral stiffness for a frame structure. However, the effect of a partition damping wall on frame stiffness is relatively small. As the loading continued, the change rate of the PDWF skeleton curve was slower than that of the TMWF. This indicates that the ductility and deformation ability of PDWF is better than that of TMWF, and its lateral resistance is weaker than that of TMWF but still higher than that of UWF. At the later stage of loading, the skeleton curve of the PDWF was significantly gentler than that of the TMWF, which means that the partition damping filler wall can significantly reduce the effect of the filler wall on the stiffness of the frame and reduce the damage of the structure under the action of earthquakes.

3.4. Comparative Analysis of Stiffness Degradation. The phenomenon of the secant line stiffness of the mode decreasing continuously with the increase of lateral displacement is called stiffness degradation. The secant line stiffness of the mode is expressed by $\mathrm{K}$ :

$$
K_{j}=\frac{\left|+p_{j}\right|+\left|-p_{j}\right|}{\left|+\delta_{j}\right|+\left|-\delta_{j}\right|},
$$




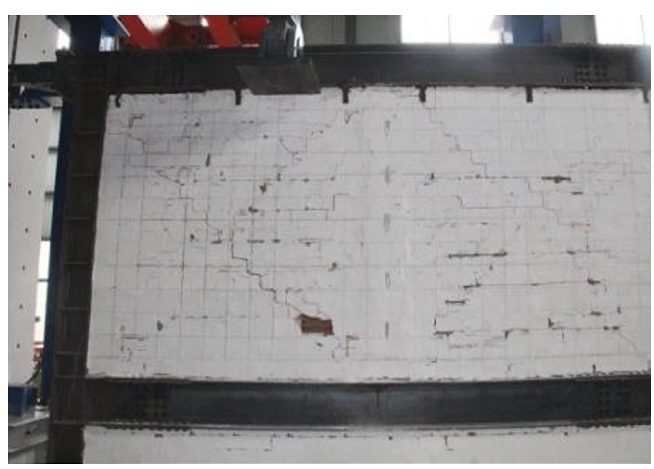

(a)

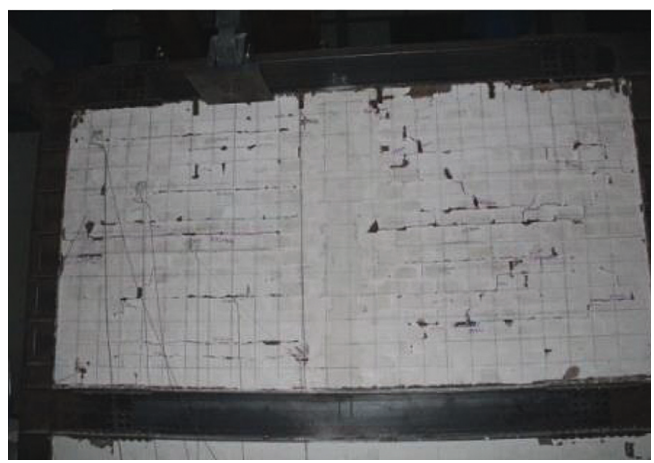

(c)

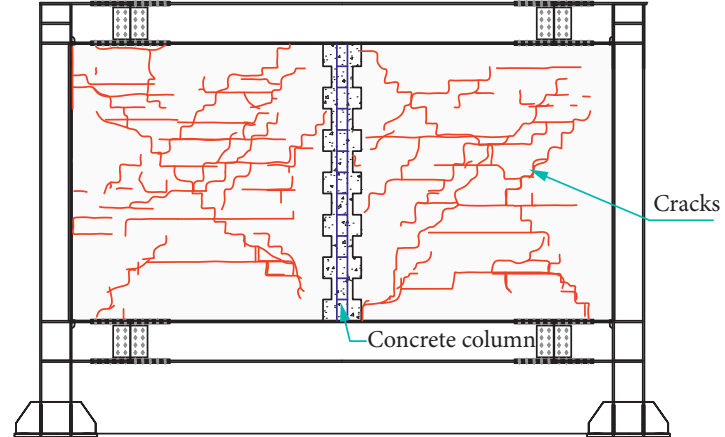

(b)

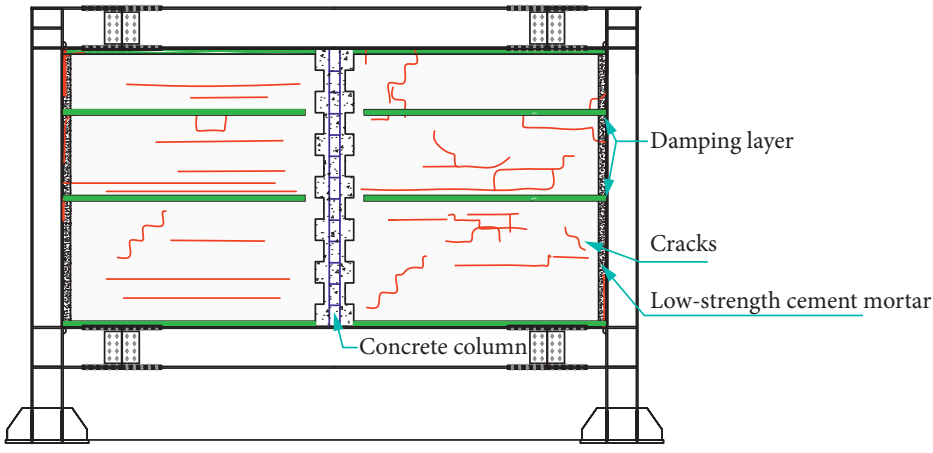

(d)

Figure 9: The failure modes of tested samples. (a) The failure mode of TMWF. (b) The crack distribution of TMWF. (c) The failure mode of PDWF. (d) The crack distribution of PDWF.

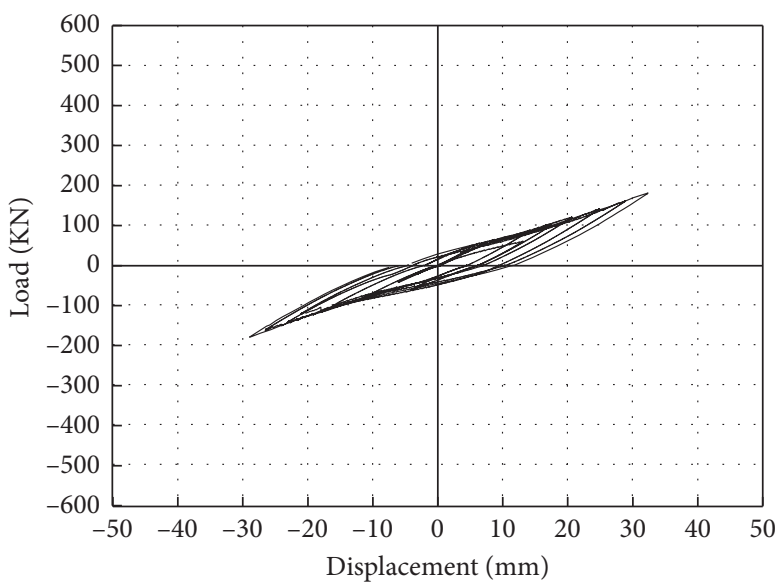

(a)

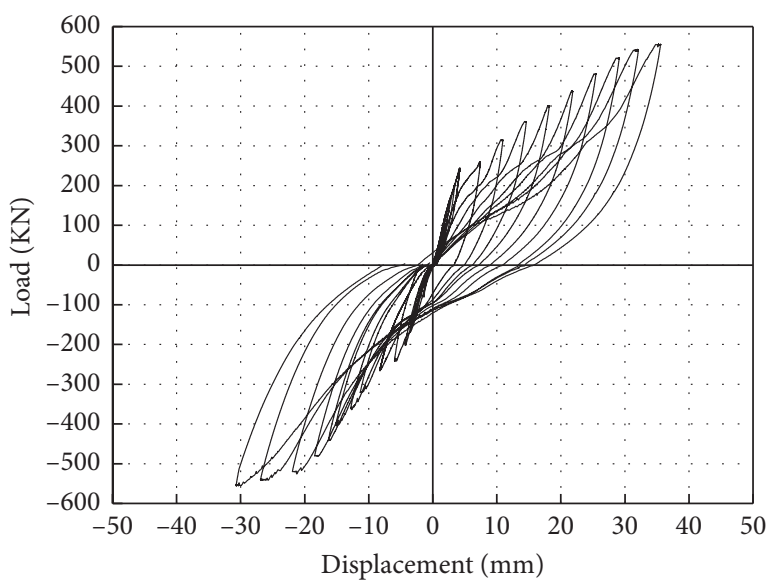

(b)

Figure 10: Continued. 


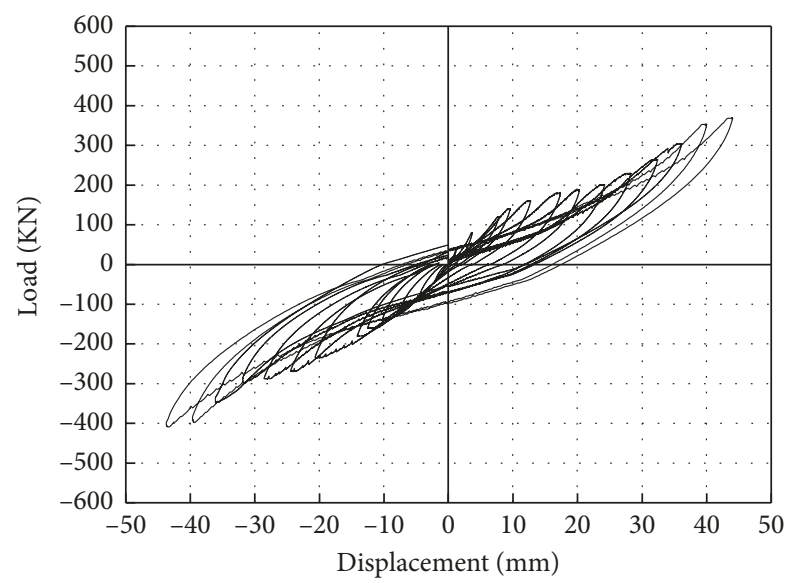

(c)

Figure 10: Hysteresis curve: (a) UWF, (b) TMWF, and (c) PDWF.

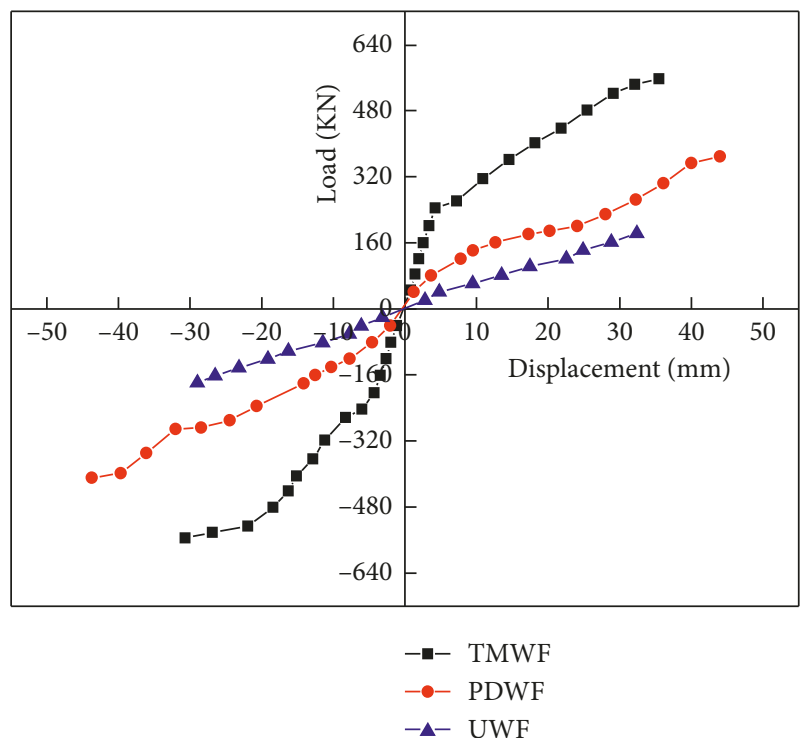

FIgURE 11: Skeleton curve.

where $K_{j}$ is the secant stiffness of the mode loaded at the $j$ level; peak load of class $j$ is $p_{j}$ loading; and $\delta_{j}$ is the displacement corresponding to the $j$-class peak load.

The change curve of secant stiffness with the displacement of each mode is drawn as shown in Figure 12, and the stiffness degradation of each mode is compared and analyzed.

As seen from Figure 12, the secant stiffness of TMWF and PDWF in the early stage of loading is improved to varying degrees when compared with that of UWF, which can effectively reduce the lateral displacement of the frame structure under the action of small earthquakes. As the loading continues, the stiffness of the modes decreases, but the falling speed of PDWF is significantly slower than that of TMWF. Especially before and after wall cracking, the stiffness of the TMWF secant line degenerates most rapidly.

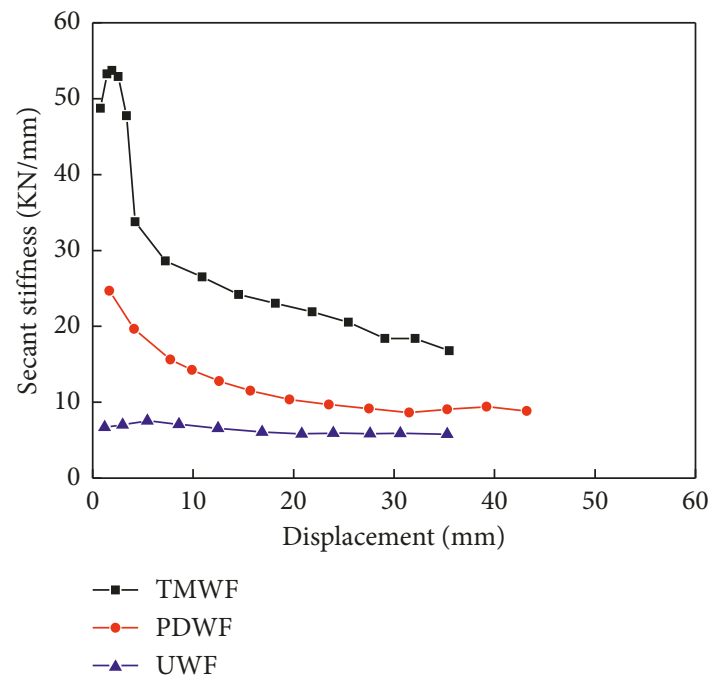

Figure 12: Stiffness degradation curve.

When the horizontal displacement was $12 \mathrm{~mm}$, the secant stiffness of PDWF was $12.9 \mathrm{~N} / \mathrm{mm}, 49 \%$ lower than that of TMWF. When the horizontal displacement is $30 \mathrm{~mm}$, the PDWF secant stiffness fell to $9.3 \mathrm{KN} / \mathrm{mm}, 51 \%$ lower than TMWF; this shows the displacement between the layers of the filler wall partition-type damping enhancement and the effect on the stiffness of the frame. The traditional masonry filler wall was greatly weakened in comparison. The damping layer helps extend the natural vibration period of structure and thus the ability to reduce the reaction of the structure under severe earthquakes. For late loading, when the horizontal displacement is $43.2 \mathrm{~mm}$, the secant stiffness of PDWF was $8.9 \mathrm{KN} / \mathrm{mm}$; the UWF secant stiffness was relatively close, but at this time, it was close to pure framework of secant stiffness. Between the filling wall and frame column, the construction measures of low-strength mortar can realize the "flame-decreasing stiffness effect of adverse effect" expectations of the mechanism. 
3.5. Comparative Analysis of Energy Consumption Capacity. According to the Specification for Seismic Test of Buildings (JGJ/T 101-2015) [49], the energy dissipation capacity of the modes should be measured by the area surrounded by the load-deformation hysteretic curve. The energy dissipation coefficient $E$ is usually used to evaluate

$$
E=\frac{S_{(\mathrm{ABC}+\mathrm{CDA})}}{S_{(\mathrm{OBE}+\mathrm{ODF})}},
$$

where $S_{(\mathrm{ABC}+\mathrm{CDA})}$ is the area surrounded by the hysteresis curve in Figure 13. $S_{(\mathrm{OBE}+\mathrm{ODF})}$ is the sum of the area of triangles $\mathrm{OBE}$ and $\mathrm{ODF}$ in Figure 13.

The energy dissipation coefficient $E$ of both TMWF and PDWF was calculated, and the relationship curve between the energy dissipation coefficient $E$ and displacement is shown in Figure 14.

At the early stage of loading, the energy dissipation capacity of UWF, PDWF, and TMWF was weak. As the loading continues, the growth rate of energy dissipation coefficient $E$ slows down or even drops to a certain extent, which is directly related to the fact that the low-strength mortar in PDWF is gradually crushed and no longer involved in energy dissipation. The sample TMWF dissipates energy through the shear slip of the filler wall, so the energy dissipation coefficient $E$ suddenly increases. In the later stage of loading, due to the rapid development of TMWF wall cracks, the energy dissipation coefficient $E$ is higher than that of PDWF. However, this energy dissipation capacity is increased at the cost of serious damage to the wall, which undoubtedly increases the repair costs of the filler wall. In comparison, the damage degree of PDWF filler wall is lighter than that of TMWF, but the energy dissipation capacity of the two is not much different, which is directly related to the damage of the low-strength mortar and the damping layer set in the construction measures. Among them, the construction measures of the low-strength mortar set between the wall frames and the energy-dissipating damping layer set separately in the wall not only ensure that the energy-dissipating capacity of the structure does not decline but also protects the filler wall.

3.6. Contrastive Analysis of the Lateral Displacement of Frame Columns. According to the lateral displacement of the three modes at different heights of the frame column, D1 represents the horizontal displacement of the top of the frame column, D2 represents the horizontal displacement of the frame column, and D3 represents the horizontal displacement of the bottom of the frame column. The lateral displacement and variation diagram was drawn, as shown in Figure 15.

According to the comparison and analysis of the chart, under the same grade of load, the TMWF side shift is the smallest, the PDWF is the second largest, and the UWF side shift is the largest. At the early loading stage, both TMWF and PDWF can significantly reduce the lateral displacement of the frame. With the continuation of loading, the deformation capacity of mode TMWF is still far from that of mode UWF,

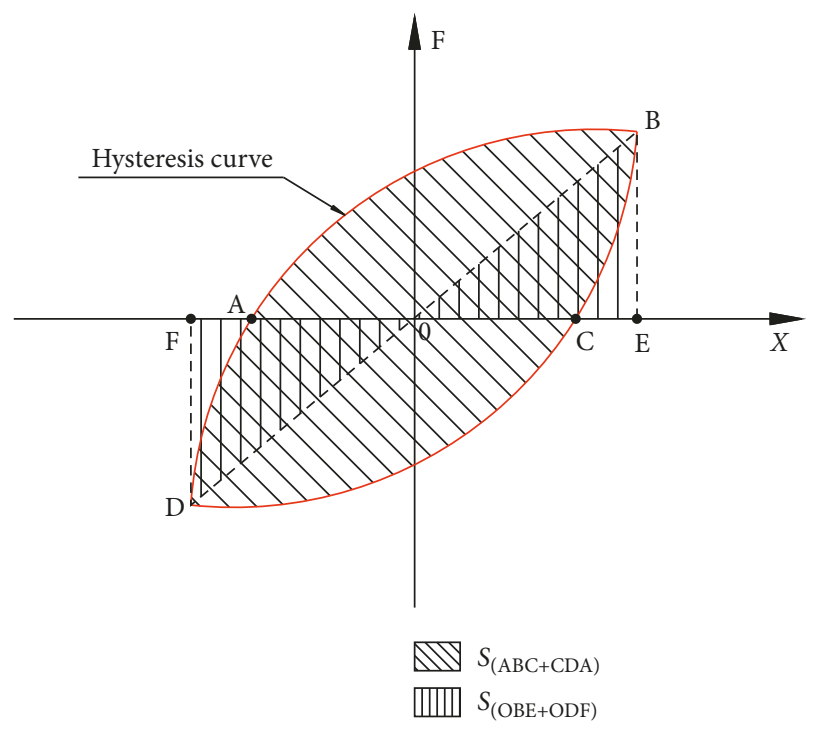

FIgURE 13: Schematic diagram of the calculation of energy dissipation coefficient $E$.

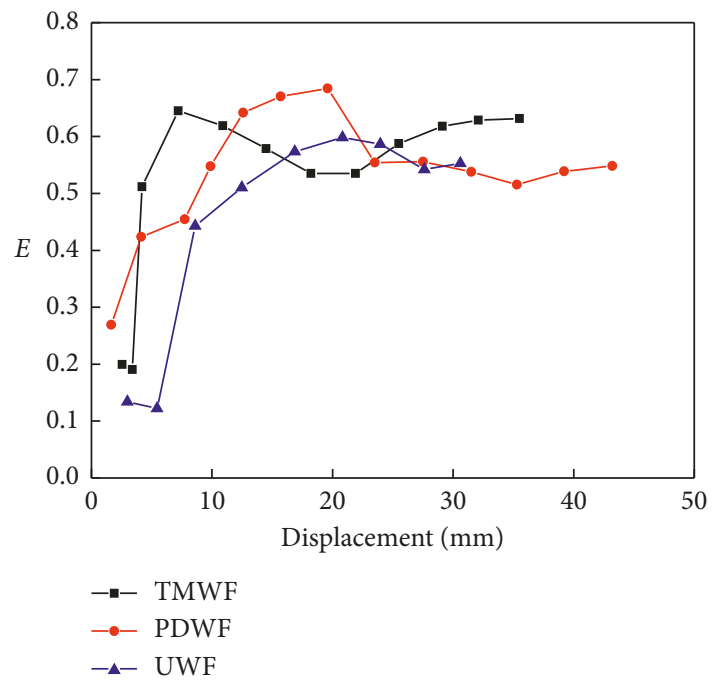

FIGURE 14: Energy dissipation curve.

which indicates that the free deformation of the frame is severely constrained by the existence of the filler wall. It is easy for the structure to form a weak layer, which makes it difficult to realize the expected "strong-column weak-beam" mechanism and greatly increases the damage of the filler wall itself. Furthermore, the deformation ability of mode PDWF with low-strength mortar is damaged more closely to that of mode UWF. For the protection of the filler wall at the same time, it also gradually weakens or even eliminates the filler wall lateral restraint function on the framework, making the structure ductility increase and thereby reducing the effects of the filler wall stiffness under severe earthquakes. At the same time, it provides space for the horizontal movement of the frame and allows the damping layer to play its role of energy consumption. 


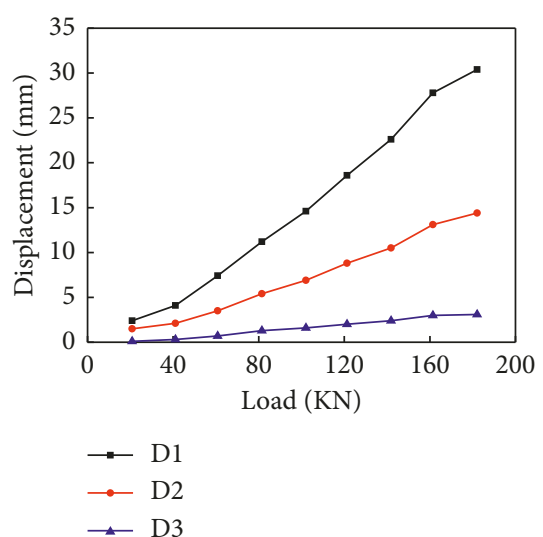

(a)

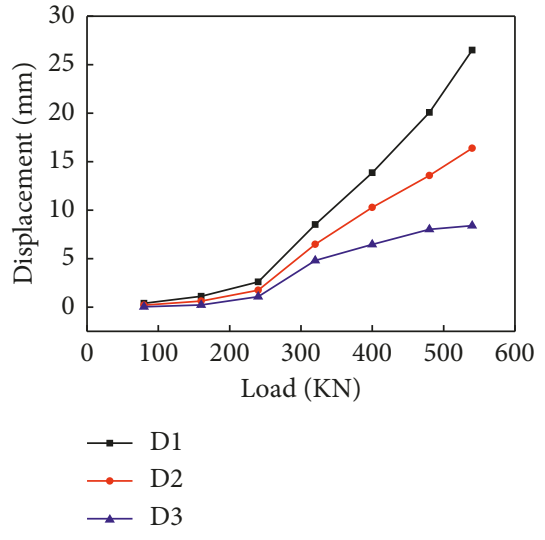

(b)

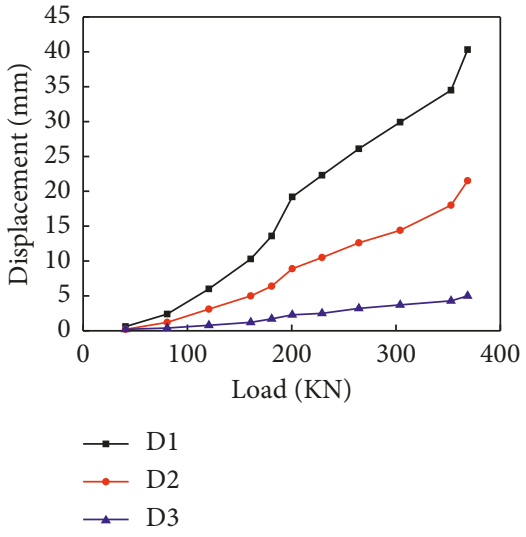

(c)

Figure 15: Displacement of the frame columns at different heights: (a) UWF, (b) TMWF, and (c) PDWF.

\section{Conclusion}

(1) The structural measures of filler low-strength mortar and laying damping layer change the stress mode of the wall and make the failure form of the wall change from an $x$-shaped cross inclined crack to horizontal crack. The main reason is that the failure of low-strength mortar in the damping filler wall frame structure isolates the interaction between the filler wall and the frame and weakens the diagonal bracing effect of the filler wall. The rigid layer in the damping layer blocks the path generated by oblique cracks of the filler wall and changes the distribution of internal forces and failure forms of the filler wall.

(2) The traditional masonry filler wall frame structure and the partition damping filler wall frame structure have different energy dissipation mechanisms, and their energy dissipation capacity is not much different. Besides, the hysteretic loop shape and area of damping filler wall frame structure under cyclic loading are more uniform, and its hysteretic energy dissipation performance is more stable.

(3) The stiffness degradation rate of the damping filler wall frame structure is obviously slower than that of the traditional masonry filler wall frame structure, and the lateral displacement value of the frame column is between the traditional masonry filler wall and the empty frame structure, which has better ductility and deformation ability.

(4) The experimental results show that the damped wall frame structure has a better seismic performance than the traditional masonry wall frame structure. In order to achieve better seismic effect, the research on materials, strength, setting thickness, setting number, and spacing of damping layer of low-strength mortar in damping filler wall frame structure will be the focus of future research.

\section{Data Availability}

The data used to support the findings of this study are available from the corresponding author upon request.

\section{Conflicts of Interest}

The authors declare that there are no conflicts of interest regarding the publication of this paper.

\section{Authors' Contributions}

Zhai Shuainan and Zou Zuyin contributed equally.

\section{Acknowledgments}

The authors sincerely thank the Scientific Research and Innovation Team Project of Sichuan Educational Committee (no. 16TD0006), the Sichuan Higher Education Engineering Research Center for Disaster Prevention and Mitigation of Village Construction, and Sichuan Agricultural University (no. CDPMV1403).

\section{References}

[1] EN 1998, Eurocode 8: Design of Structures for Earthquake Resistance. Part 1: General Rules. Seismic Actions and Rules for Buildings, European Committee for Standardization, Brussels, Belgium, 1998.

[2] NCSE-02, Norma de Construcción Sismorresistente: Parte General y Edificación, Ministerio de Fomento, Madrid, Spain, 2002.

[3] FEMA, NEHRP Recommended Provisions for Seismic Regulations for New Buildings and Other Structures, FEMA, Washington, DC, USA, 2009.

[4] INN 1996. Earthquake resistant design of buildings (INN, 1996). Norma Chilena Oficial NCh 433.Of 1996 Modificada en; 2009.

[5] Asociación Colombiana de Ingeniería Sísmica, NSR-10 Reglamento Colombiano de Construcción Sismo Resistente, Asociación Colombiana de Ingeniería Sísmica, Bogotá, Colombia, 2010. 
[6] China Architecture \& Building Press, GB 50011-2010 Code for Seismic Design of Buildings, China Architecture \& Building Press, Beijing, China, 2011.

[7] Civil and Structural Groups of Tsinghua University, Southwest Jiaotong University, and Beijing Jiaotong University, "Analysis on seismic damage of building in the Wenchuan earthquake," Journal of Building Structures, vol. 29, no. 4, pp. 1-9, 2008, in Chinese.

[8] P. Yan, B. Sun, and H. Zhang, "Seismic damage to RC frame teaching buildings in Lushan MS7.0 earthquake," China Civil Engineering Journal, vol. 47, no. s1, pp. 24-28, 2014.

[9] K. Goda, T. Kiyota, R. M. Pokhrel et al., "The 2015 Gorkha Nepal earthquake: insights from earthquake damage survey," Frontiers in Built Environment, vol. 1, p. 8, 2015.

[10] A. Fragomeli, A. Galasco, F. Graziotti et al., "Comportamento degli edifici in muratura nella sequenza sismica dell'Italia central del 2016-parte 1: quadro generale (in Italian)," Progettazione Sismica, vol. 8, no. 2, pp. 49-77, 2017.

[11] G. Al-Chaar, M. Issa, and S. Sweeney, "Behavior of masonryinfilled nonductile reinforced concrete frames," Journal of Structural Engineering, vol. 128, no. 8, pp. 1055-1063, 2002.

[12] M. Dolšek and P. Fajfar, "The effect of masonry infills on the seismic response of a four-storey reinforced concrete frame -a deterministic assessment," Engineering Structures, vol. 30, no. 7, pp. 1991-2001, 2008.

[13] P. B. Shing and A. Stavridis, "Analysis of seismic response of masonry-infilled RC frames through collapse," ACI Structural Journal, vol. 297, pp. 1-20, 2014.

[14] S. H. Basha and H. B. Kaushik, "Behavior and failure mechanisms of masonry-infilled RC frames (in low-rise buildings) subject to lateral loading," Engineering Structures, vol. 111, pp. 233-245, 2016.

[15] Y. Zhang, M. Zhou, and L. Zheng, "Seismic fragility analysis of infilled reinforced concrete frame building based on modified Ibarra-Medina-Krawinkler model," Journal of Chongqing University, vol. 41, no. 3, pp. 67-75, 2018.

[16] T. Paulay and M. J. Priestley, Seismic Design of Reinforced Concrete and Masonry Buildings, John Wiley \& Sons, New York, NY, USA, 1992.

[17] M. Preti, N. Bettini, and G. Plizzari, "Infill walls with sliding joints to limit infill-frame seismic interaction: large-scale experimental test," Journal of Earthquake Engineering, vol. 16, no. 1, pp. 125-141, 2012.

[18] P. G. Asteris, S. T. Antoniou, D. S. Sophianopoulos, and C. Z. Chrysostomou, "Mathematical macromodeling of infilled frames: state of the art," Journal of Structural Engineering, vol. 137, no. 12, pp. 1508-1517, 2011.

[19] D. Celarec and M. Dolšek, "Practice-oriented probabilistic seismic performance assessment of infilled frames with consideration of shear failure of columns," Earthquake Engineering \& Structural Dynamics, vol. 42, no. 9, pp. 1339-1360, 2013.

[20] L. Cavaleri and F. Di Trapani, "Prediction of the additional shear action on frame members due to infills," Bulletin of Earthquake Engineering, vol. 13, no. 5, pp. 1425-1454, 2015.

[21] M. Mohammadi and V. Akrami, "An engineered infilled frame: behavior and calibration," Journal of Constructional Steel Research, vol. 66, no. 6, pp. 842-849, 2010.

[22] M. Preti, L. Migliorati, and E. Giuriani, "Experimental testing of engineered masonry infill walls for post-earthquake structural damage control," Bulletin of Earthquake Engineering, vol. 13, no. 7, pp. 2029-2049, 2014.

[23] Y. Zhou, Y. Guo, Y. Liao et al., "Experimental study on the performances of damped infill wall unit," China Civil
Engineering Journal, vol. 46, no. 5, pp. 56-63, 2013, in Chinese.

[24] Y. Zhou, Y. Guo, G. Yang et al., "Experimental study on seismic behavior of frame structure with damped infill wall," Journal of Building Structures, vol. 34, no. 7, pp. 89-96, 2013.

[25] Y. Zhou, Y. Guo, Y. Liao et al., "Experimental study on seismic behaviors of damped masonry infilled reinforced concrete frame structures with SBS layers," China Civil Engineering Journal, vol. 47, no. 9, pp. 21-28, 2014, in Chinese.

[26] A. S. Tasligedik and S. Pampanin, "Rocking cantilever clay brick infill wall panels: a novel low damage infill wall system," Journal of Earthquake Engineering, vol. 21, no. 7, pp. 1-27, 2016.

[27] N. Verlato, G. Guidi, P. Da, and C. Modena, "Innovative systems for masonry infill walls based on the use of deformable joints: combined in-plane/out-of-plane tests," in Proceedings of the 16th International Brick and Block Masonry Conference (IBMAC 2016), pp. 1359-1366, Padova, Italy, June 2016.

[28] P. Morandi, R. R. Milanesi, and G. Magenes, "Innovative seismic solution for clay masonry infills with sliding joints: principles and details," in Proceedings of the 16th International Brick and Q3 Block Masonry Conference (IBMAC 2016), pp. 1273-1282, Padova, Italy, June 2016.

[29] M. Preti and V. Bolis, "Masonry infill construction and retrofit technique for the infill-frame interaction mitigation: test results," Engineering Structures, vol. 132, pp. 597-608, 2017.

[30] I. S. Misir, O. Ozcelik, S. C. Girgin, and S. Kahraman, "Experimental work on seismic behavior of various types of masonry infilled RC frames," Structural Engineering and Mechanics, vol. 44, no. 6, pp. 763-774, 2012.

[31] C. E. Adamis, E. Vintzileou, and V. Palieraki, "In-plane and out-of-plane response of a mosonry infill divided into smaller wallettes," in Proceedings of the 16th International Brick and Block Masonry Conference (IBMAC 2016), Padova, Italy, June 2016.

[32] L. Silva, G. Vasconcelos, P. B. Lourenço, and F. Akhoundi, "Experimental evaluation of a constructive system for earthquake resisting masonry enclosure walls," in Proceedings of the 16th International Brick and Block Masonry Conference (IBMAC 2016), Padova, Italy, June 2016.

[33] Y. Totoev and A. Al Harthy, "Semi interlocking masonry as infill wall system for earthquake resistant buildings: a review," Journal of Engineering Research, vol. 13, no. 1, pp. 33-41, 2016.

[34] M. Vailati and G. Monti, "Earthquake-resistant and thermoinsulating infill panel with recycled-plastic joints," in Springer Natural Hazards, S. D'Amico, Ed., Springer International Publishing, Cham, Switzerland, pp. 417-432, 2016.

[35] X. Palios, M. N. Fardis, E. Strepelias, and S. N. Bousias, "Unbonded brickwork for the protection of infills from seismic damage," Engineering Structures, vol. 131, pp. 614624, 2017.

[36] D. Markulak, I. Radić, and V. Sigmund, "Cyclic testing of single bay steel frames with various types of masonry infill," Engineering Structures, vol. 51, pp. 267-277, 2013.

[37] M. Preti, N. Bettini, L. Migliorati, V. Bolis, A. Stavridis, and G. A. Plizzari, "Analysis of the in-plane response of earthen masonry infill panels partitioned by sliding joints," Earthquake Engineering \& Structural Dynamics, vol. 45, no. 8, pp. 1209-1232, 2016.

[38] M. Preti, V. Bolis, and A. Stavridis, "Seismic infill-frame interaction of masonry walls partitioned with horizontal sliding joints: analysis and simplified modeling," Journal of Earthquake Engineering, vol. 23, no. 10, pp. 1651-1677, 2017. 
[39] M. Mohammadi, V. Akrami, and R. Mohammadi-Ghazi, "Methods to improve infilled frame ductility," Journal of Structural Engineering, vol. 137, no. 6, pp. 646-653, 2011.

[40] V. Bolis and M. Preti, "Openings in infills with horizontal sliding joints: a parametric study to support the design," Bulletin of Earthquake Engineering, vol. 17, no. 9, pp. 51015132, 2019.

[41] V. Bolis, A. Paderno, and M. Preti, "Infill with sliding panels in presence of a full-height opening: experimental in-plane response," Engineering Structures, vol. 197, Article ID 109368, 2019.

[42] F. Graziotti, U. Tomassetti, S. Sharma, L. Grottoli, and G. Magenes, "Experimental response of URM single leaf and cavity walls in out-of-plane two-way bending generated by seismic excitation," Construction and Building Materials, vol. 195, pp. 650-670, 2019.

[43] U. Tomassetti, L. Grottoli, S. Sharma, and F. Graziotti, "Dataset from dynamic shake-table testing of five full-scale single leaf and cavity URM walls subjected to out-of-plane two-way bending," Data in Brief, vol. 24, Article ID 103854, 2019.

[44] O. Ozturkoglu, T. Ucar, and Y. Yesilce, "Effect of masonry infill walls with openings on nonlinear response of reinforced concrete frames," Earthquakes and Structures, vol. 12, no. 3, pp. 333-347, 2017.

[45] GB/T. 51232-2016, Technical Standard for Assembled Buildings with Steel-Structure, China Architecture \& Building Press, Beijing, China, 2017.

[46] GB 50003-2011, Code for Design of Masonry Structures, China Architecture \& Building Press, Beijing, China, 2012.

[47] GB/T2542-2012, Test Methods for Brick Wall Bricks, China Architecture \& Building Press, Beijing, China, 2013.

[48] JGJ/T70-2009, Standards for Testing Basic Performance of Building Mortars, China Architecture \& Building Press, Beijing, China, 2009.

[49] JGJ/T 101-2015, Specification for Seismic Test of Buildings, China Architecture \& Building Press, Beijing, China, 2015. 


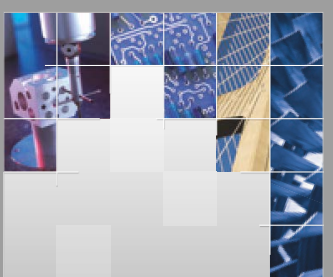

\section{Enfincering}
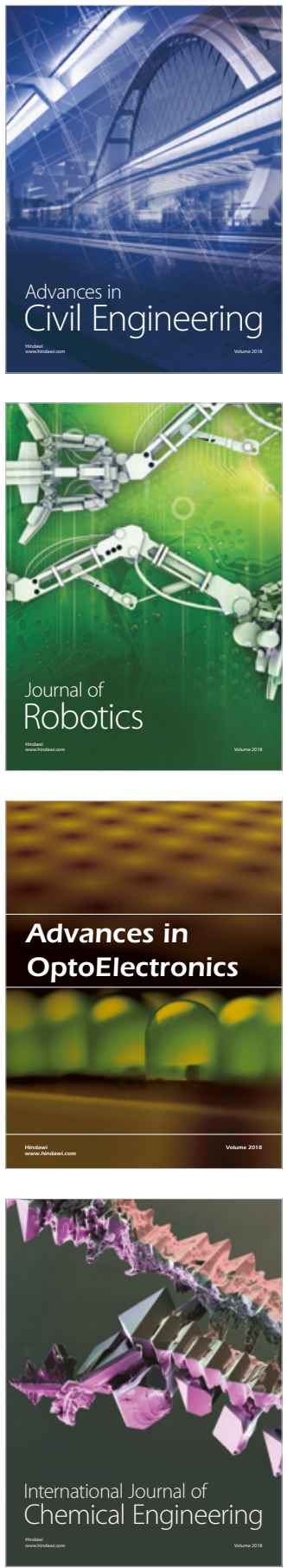

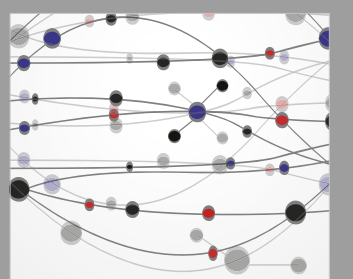

\section{Rotating \\ Machinery}

The Scientific World Journal

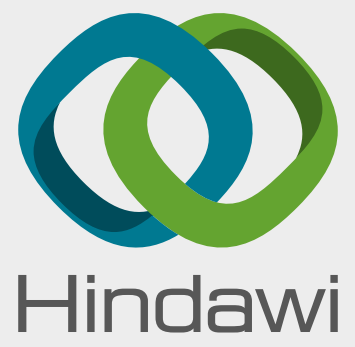

Submit your manuscripts at

www.hindawi.com
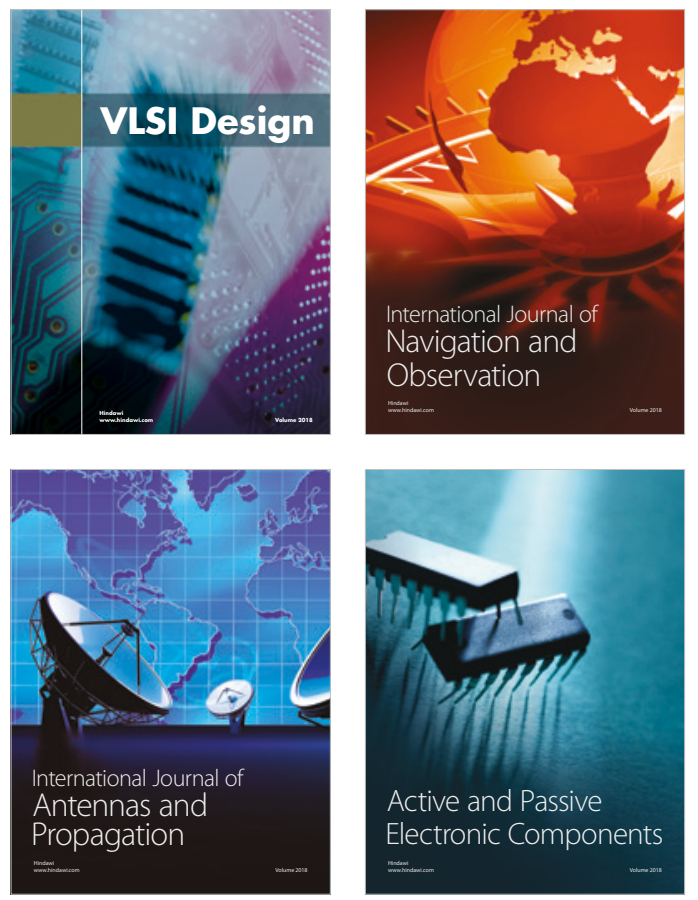
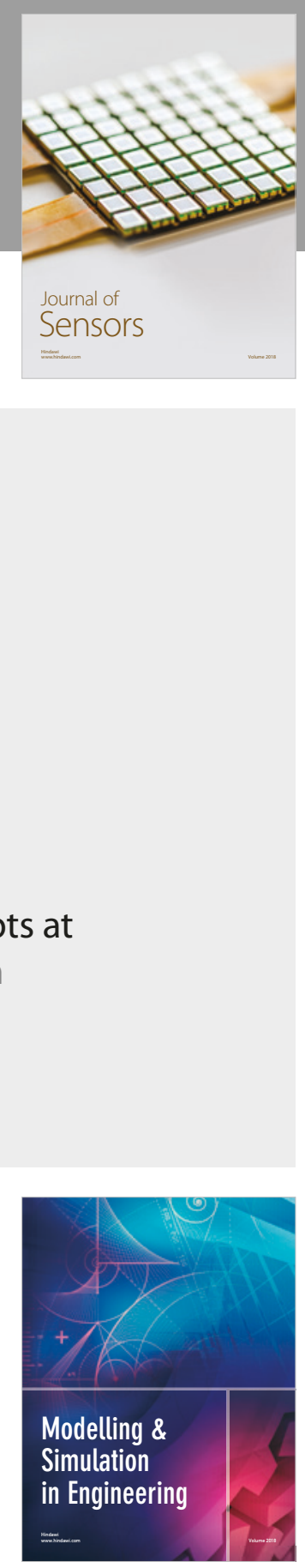

\section{Advances \\ Multimedia}
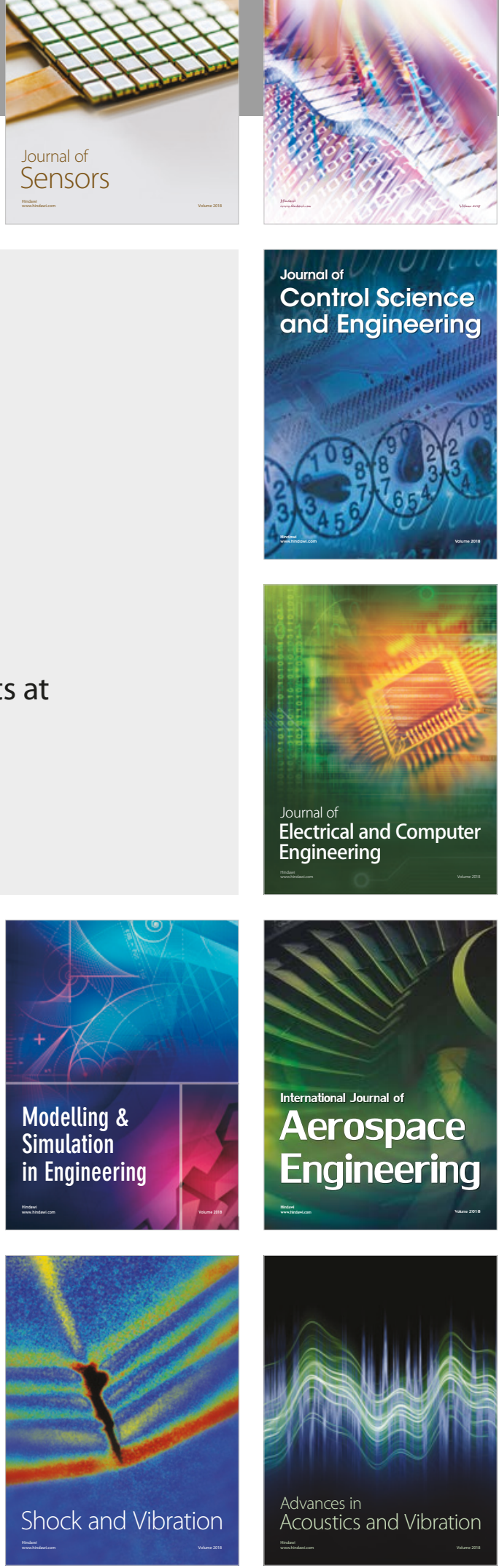